九州大学学術情報リポジトリ

Kyushu University Institutional Repository

\title{
Effect of Synthetic Food Colorings on Immunoglobulin Production by Rat Lymphocytes
}

Kuramoto, Yuichiro

Laboratory of Food Science, Department of Food Science and Technology, Faculty of Agriculture, Kyushu University

Tsuruta, Osamu

Meito Industries Co.

Tachibana, Hi rofumi

Laboratory of Food Science, Department of Food Science and Technology, Faculty of Agriculture, Kyushu University

Sugano, Michihiro

Faculty of Human Life Sciences, Prefectural University of Kumamoto

他

https://doi.org/10.5109/24206

出版情報：九州大学大学院農学研究院紀要. 42 (1/2)，pp. 193-201，1997-12. Kyushu University バージョン：

権利関係 : 


\title{
Effect of Synthetic Food Colorings on Immunoglobulin Production by Rat Lymphocytes
}

\author{
Yuichiro Kuramoto,,** Osamu Tsuruta, ${ }^{1,}$ Hirofumi Tachibana,' \\ Michihiro Sugano ${ }^{3}$ and Koji Yamada ${ }^{1}$
}

\author{
${ }^{1}$ Laboratory of Food Science, Department of Food Science and Technology, \\ Faculty of Agriculture, Kyushu University, 6-10-1 Hakozaki, Higashi-ku, \\ Fukuoka 812-81, ${ }^{2}$ Meito Industries Co., Fukuma, 811-32 and \\ Faculty of Human Life Sciences, Prefectural University of \\ Kumamoto, Kumamoto 862, Japan. \\ (Received July 30, 1997 and accepted August 25, 1997)
}

\begin{abstract}
The effect of 4 azo dyes and 5 non-azo dyes used for food coloring on immunoglobulin (Ig) production by rat spleen and mesenteric lymph node (MLN) lymphocytes was examined. The amounts of IgG and IgM produced by MLN lymphocytes after $72 \mathrm{hr}$ cultivation were the same as those of control culture in the presence of $10^{-1}$ and $10^{2} \mu \mathrm{M}$ azo dyes. On the other hand, amaranth inhibited $\operatorname{IgE}$ to control level at $10^{3} \mu \mathrm{M}$ while $\operatorname{IgE}$ level was 1.5 times higher than control for new coccine and sunset yellow FCF. With regard to non-azo colorings, sodium $\mathrm{Cu}$ chlorophyllin inhibited IgE production by both lymphocytes at the concentrations between $10^{\circ}$ and $10^{\prime} \mu \mathrm{M}$.Among chlorophyll derivatives, $\mathrm{Cu}$ - and Fe-derivatives inhibited IgE production by both lymphocytes.Among Mg-derivatives, chlorophyll-b, having aldehyde group as the constituent, enhanced it by both lymphocytes. These results suggest that minerals and aldehyde in porphyllin ring have an important role in the regulation of $\mathrm{IgE}$ production.
\end{abstract}

\section{INTRODUCTION}

Our life style, especially dietary life style, has changed in the last four decades. It is suggested that following environmental changes has resulted in increase of allergic patients. It is reported that diesel exhaust particulates (DEP) have an adjuvant effect on IgE production (Muranaka et al., 1986; Takafuji et al., 1987, 1989; Takenaka et al., 1995). With regard to our life style, chronic exposure of rats to cigarette smoke has resulted in inhibition the antibody-forming cell response to both $\mathrm{T}$ cell-dependent and -independent antigens and reflect B cell dysfunction (Savage et al., 1991).

Focused on our daily food, we are surrounded by many food additives or chemicals. Though food additives are used for coloring, preservation, flavoring, and so on for our benefit, many adverse reactions have also been reported. For instance, sulfites causes asthmatic attack, Tartrazine reveals urticaria (Tarlo et al., 1993; Weber, 1993; Wüthrich, 1993), and annatto dye causes anaphylaxis (Nish et al., 1991). However, only a few of these agents are currently known to play a role in promoting allergic reactions and there was few information about the mechanism by which food additives enhance allergic reaction. Therefore, we focused on the effect of food additives on Ig production, which

* To whom correspondence should be addressed.

Abbreviation(s): ELISA, enzyme-linked immunosorbent assay; $\lg (\mathrm{s})$, immunoglobulin(s); MLN, mesenteric lymph node. 


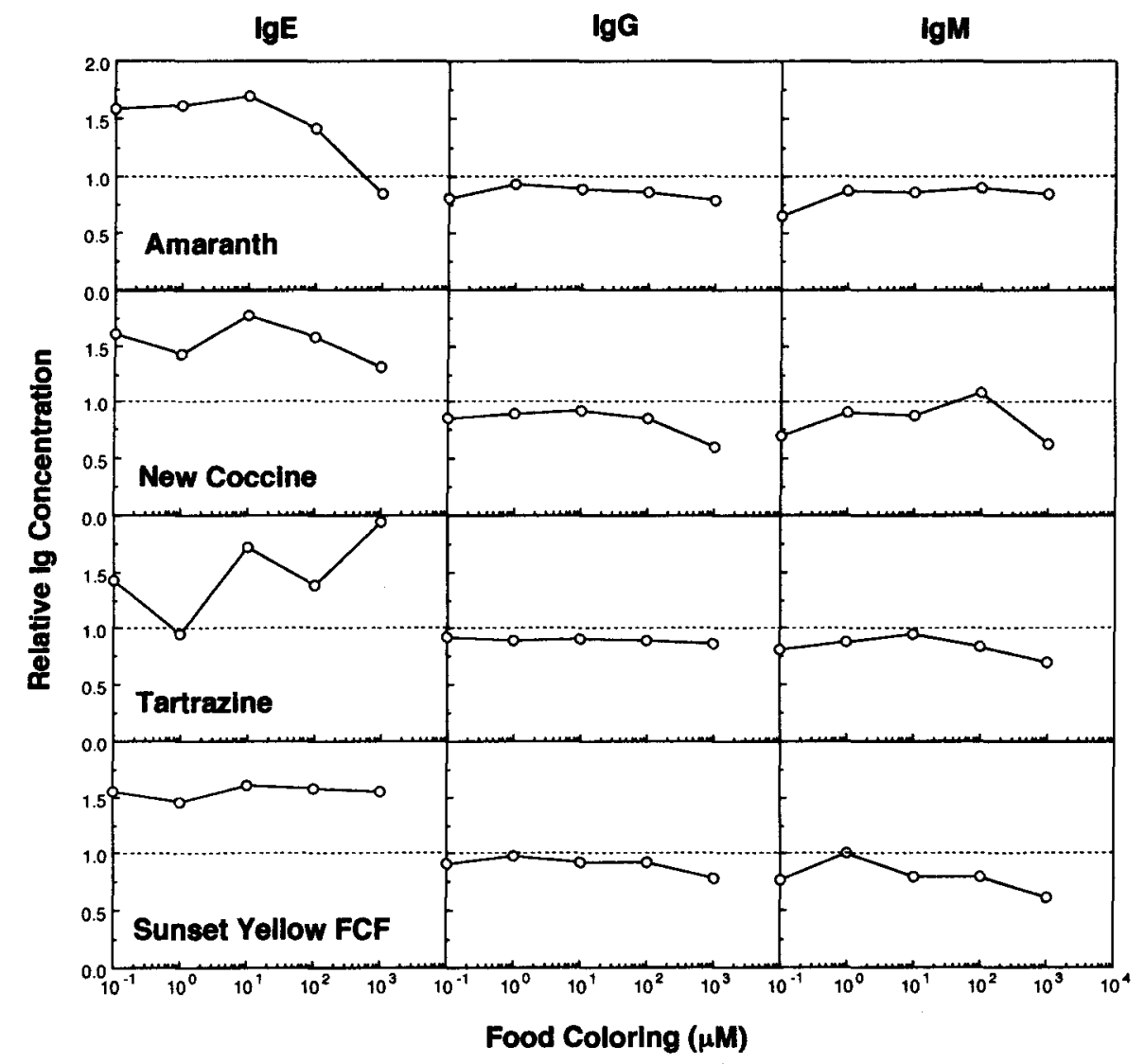

Fig. 2. Effect of azo colorings on Ig produced by rat MLN lymphocytes. MLN lymphocytes were cultured with various azo dyes at around $10^{-1}$ to $10^{3} \mu \mathrm{M}$ for $72 \mathrm{hr}$ and the culture supernatant was collected to evaluate Ig concentration.

Effect of Non-azo Food Colorings on Ig Production by Rat Spleen and MLN Lymphocytes.

We also investigated the effect of non-azo food colorings on Ig production by rat lymphocytes. The colorings used here were water-soluble annatto, brilliant blue FCF (food blue No. 1), sodium Cu-chlorophyllin, fast green FCF (food green No. 3) and indigocarmine (food blue No. 2). As shown in Fig. 3, sodium Cu-chlorophyllin inhibited IgG and IgM production at the concentrations above $10^{2} \mu \mathrm{M}$ and strongly inhibited $\operatorname{IgE}$ production at the concentrations above $10 \mu \mathrm{M}$. In addition, water-soluble annatto, fast green FCF and brilliant blue FCF also inhibited IgE production at $10^{1}$ and $10^{2} \mu \mathrm{M}$. On the other hand, water-soluble annatto, brilliant blue FCF, fast green FCF and indigocarmine showed no stimulatory or inhibitory effect on IgG and IgM production. These results 


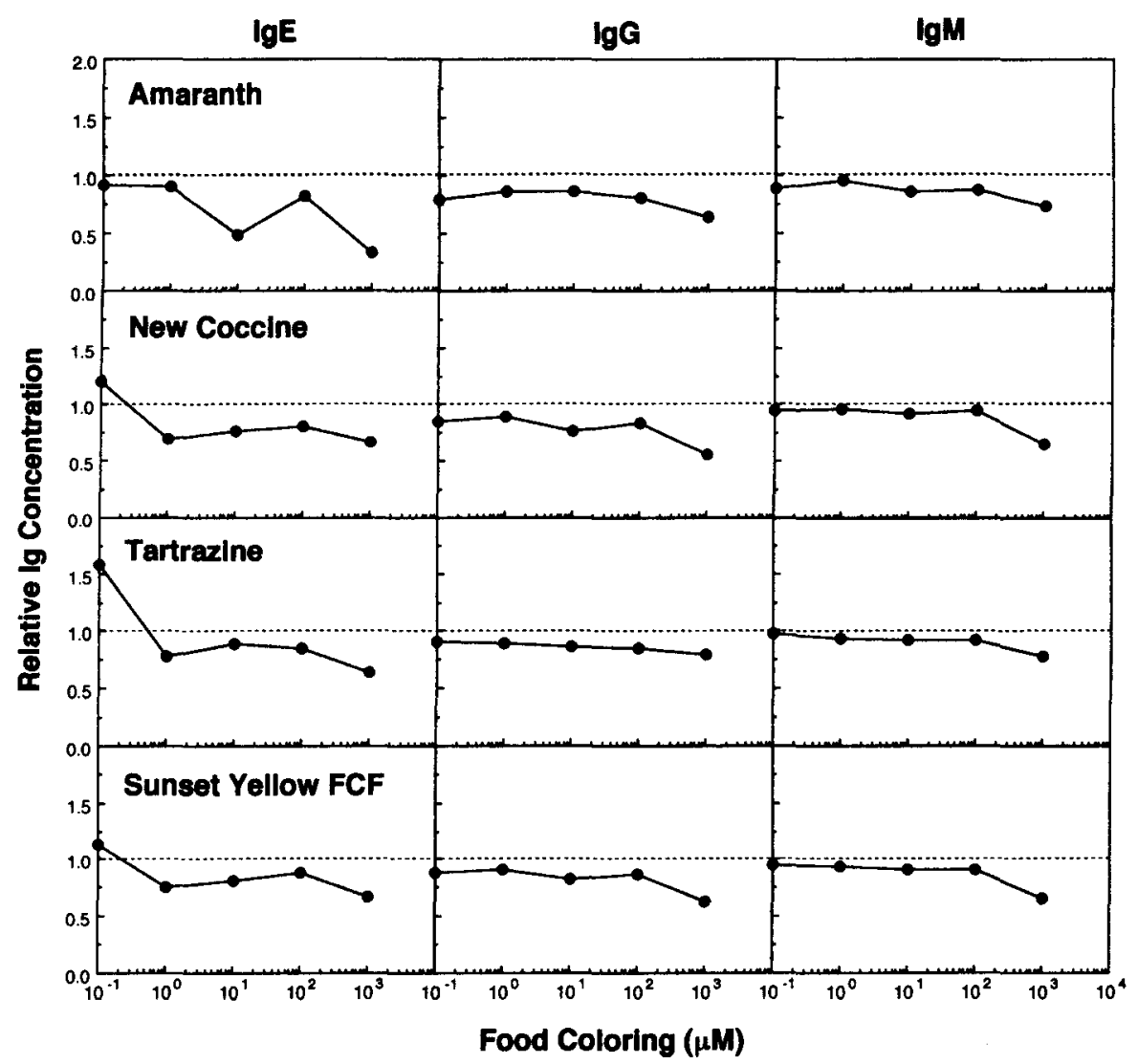

Fig. 1. Effect of azo colorings on Ig produced by rat spleen lymphocytes. Spleen lymphocytes were cultured with various azo dyes at around $10^{-1}$ to $10^{3} \mu \mathrm{M}$ for $72 \mathrm{hr}$ and the culture supernatant was collected to evaluate Ig concentration.

coccine, tartrazine and sunset yellow FCF did not affect to the IgE level at the concentrations between $10^{\circ}$ and $10^{3} \mu \mathrm{M}$, while amaranth decreased $\mathrm{IgE}$ level to half of the control level at $10^{1} \mu \mathrm{M}$.

Then, the effect of azo dyes on Ig production by rat MLN lymphocytes was examined. Since MLN plays an important role in the gut immune system and induction of food allergy, the effect of food colorings on Ig production of MLN lymphocytes was compared with that of spleen lymphocytes which are involved in the systemic immune system. As shown in Fig. 2, these azo dyes did not affect to the level of IgG and IgM at the concentrations used here as well as spleen lymphocytes. However, IgE level was 1.5 times higher than the control level in all azo dyes. On the other hand, amaranth decreased $\mathrm{IgE}$ level to control level at $10^{3} \mu \mathrm{M}$. 


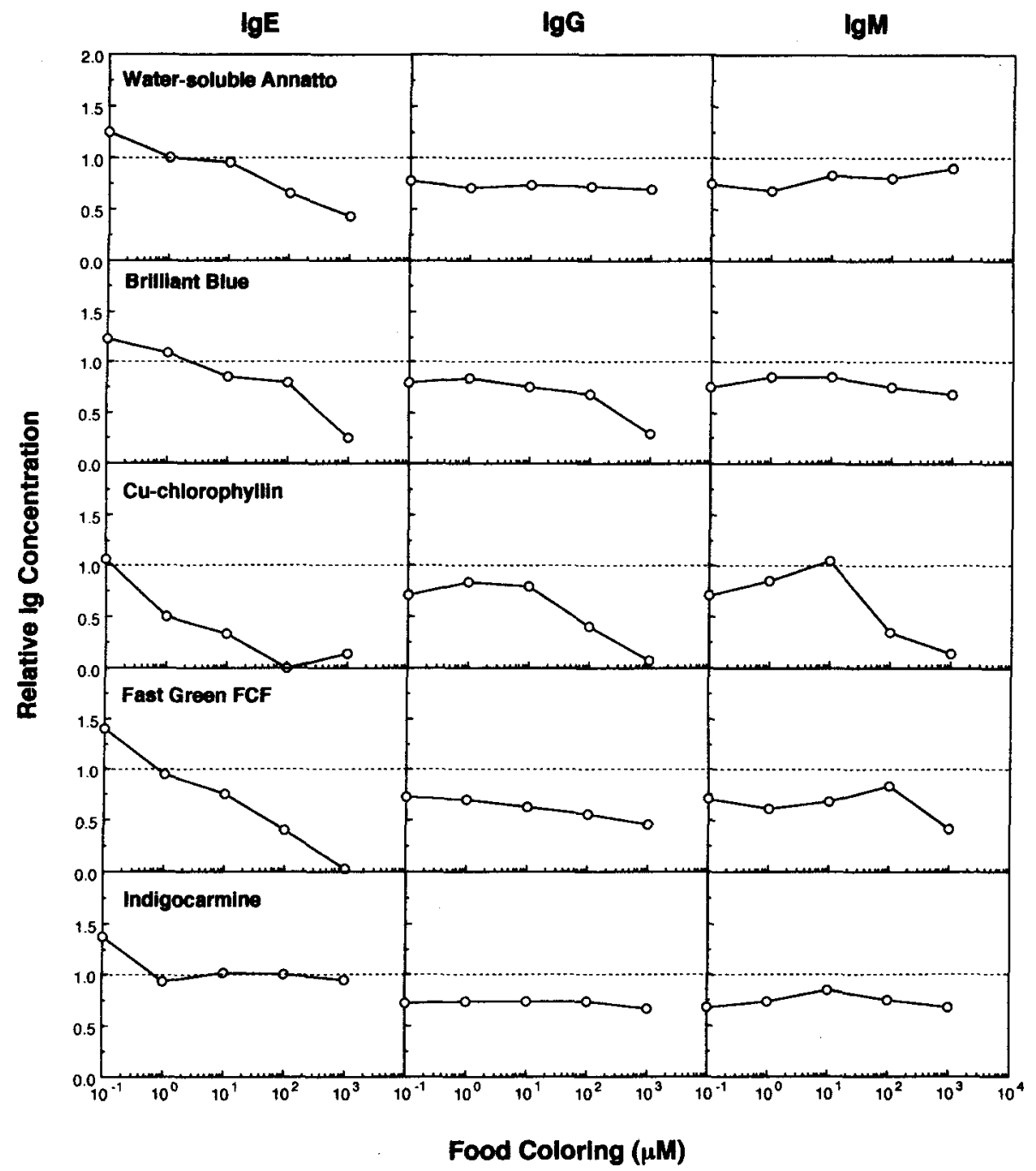

Fig. 4. Effect of triphenylmethane dyes (brilliant blue FCF and fast green FCF), indigoid dye (indigocarmine), water-soluble annatto and sodium $\mathrm{Cu}$-chlorophyllin on Ig produced by rat MLN lymphocytes. MLN lymphocytes were cultured with various colorings at around $10^{-1}$ to $10^{3} \mathrm{uM}$ for $72 \mathrm{hr}$ and the culture supernatant was collected to evaluate Ig concentration.

MLN lymphocytes was 10 times lower than that seen in spleen lymphocytes. This suggests that MLN lymphocytes are more sensitive to sodium Cu-chlorophyllin than spleen lymphocytes. On the other hand, the dyes other than sodium $\mathrm{Cu}$-chlorophyllin showed no stimulatory or inhibitory effect on IgG and IgM production. However, watersoluble annatto and fast green FCF inhibited IgE production at 10 and $10^{2} \mu \mathrm{M}$. 


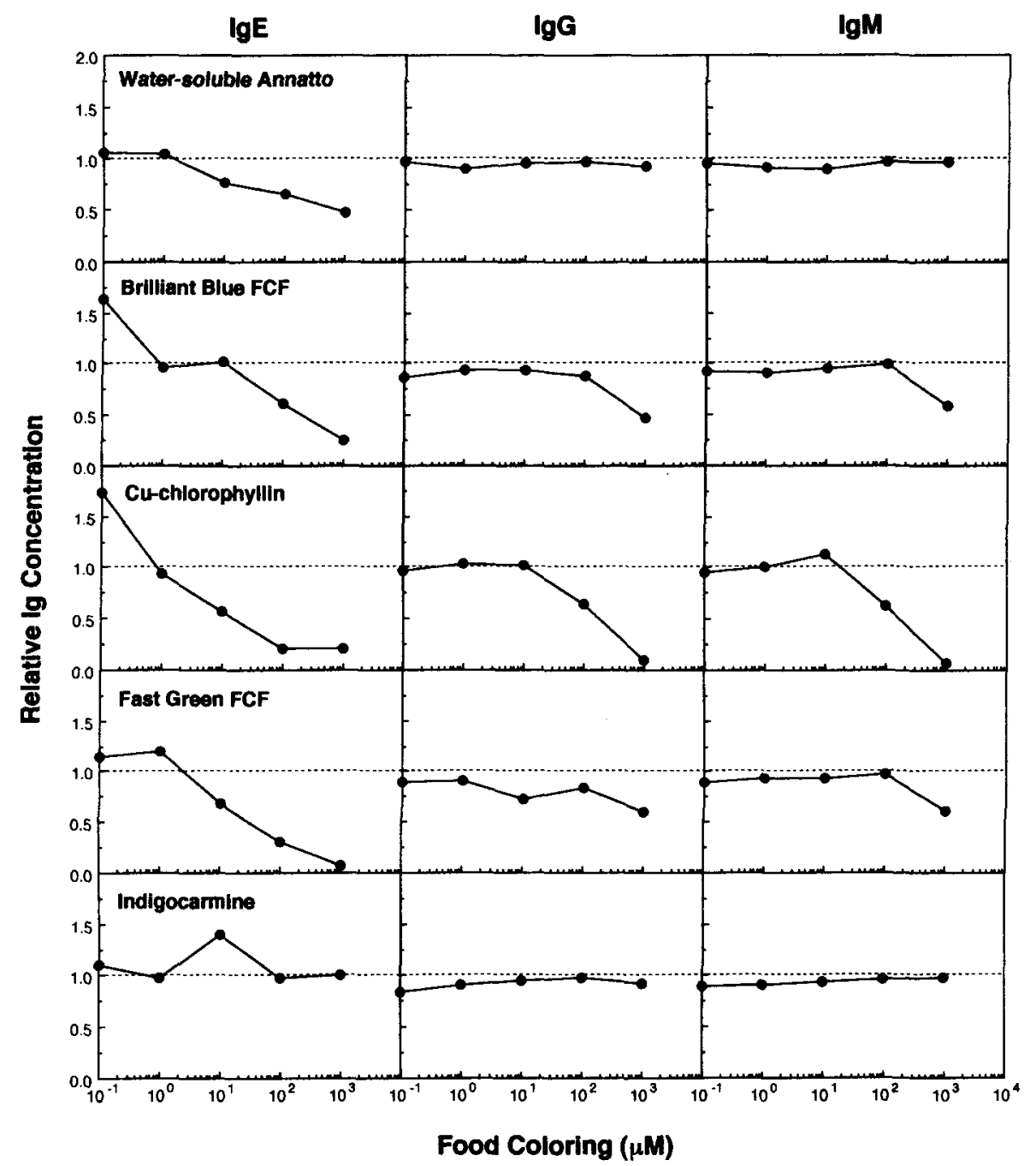

Fig. 3. Effect of triphenylmethane dyes (brilliant blue FCF and fast green FCF), indigoid dye (indigocarmine), water-soluble annatto and sodium $\mathrm{Cu}$-chlorophyllin on Ig produced by rat spleen lymphocytes. Spleen lymphocytes were cultured with various colorings at around $10^{-1}$ to $10^{3} \mathrm{\mu}$ for $72 \mathrm{hr}$ and the culture supernatant was collected to evaluate Ig concentration.

suggest that sodium Cu-chlorophyllin has an Ig production-inhibitory effect at the concentrations above $10 \mu \mathrm{M}$ and water-soluble annatto, fast green FCF and brilliant blue FCF have a selective inhibitory effect of $\operatorname{IgE}$ at 10 and $10^{2} \mu \mathrm{M}$.

In the case of MLN lymphocytes, sodium Cu-chlorophyllin strongly inhibited $\operatorname{IgE}$ production at the concentrations above $1 \mu \mathrm{M}$, and the production of $\operatorname{IgG}$ and $\operatorname{IgM}$ at $10 \mu \mathrm{M}$ (Fig. 4). The concentration, at which the inhibitory effect of this coloring was seen in 
xanthene dyes, enhanced IgE production and inhibited IgG and IgM production by rat spleen lymphocytes (Kuramoto et al., 1997). In the present study, we examined the effect of synthetic food colorings such as 4 azo and 5 non-azo dyes on Ig production by rat lymphocytes.

In the case of azo dyes, the effect on Ig production by spleen lymphocytes was negligible, but they exerted IgE production-enhancing activity in MLN lymphocytes. Lim et al. (1994b and 1995) reported that bile acid cultured with LPS in the presence of IL-4 or IL-5 inhibited IgE production by spleen lymphocytes, while it enhanced IgE production in the presence of lectins by MLN lymphocytes. These results suggest that the responses of spleen and MLN lymphocytes to food components are different from each other. In addition, as reported in the experiment which was made to establish the etiologic role of foodstuffs and/or food additives and the possible associated immunological alterations, the relationship between food additives (including tartrazine) and allergic symptoms were not correlated (Morales et al., 1995). Thus, the effect of azo dyes to the systemic immune system might be more modulate that to the gut immune system.

As for non-azo food colorings, the level of $\operatorname{IgG}$ and IgM were the same as that of control at the concentration selected in this experiment, while brilliant blue FCF and fast green FCF (categorized to triphenylmethane dyes) or sodium Cu-chlorophyllin strongly inhibited IgE produced by both spleen and MLN lymphocytes at the concentrations above 1 and $10 \mu \mathrm{M}$. In addition, the inhibition of IgE production was induced by $\mathrm{Cu}-$ and $\mathrm{Fe}-$ chlorophyllin, but not $\mathrm{Mg}$-chlorophyllin. It had been reported that the toxicity of sodium Cu-chlorophyllin was derived from free $\mathrm{Cu}^{2+}$ (Worden et al., 1955). Steffensen et al. (1994) reported that cell membrane of human $\mathrm{T}$ and $\mathrm{B}$ lymphocytes and monocytes were more strongly damaged by $\mathrm{Cu}^{2+}$ than by $\mathrm{Pb}^{2+}$ or $\mathrm{Zn}^{3+}$ by scanning electron microscopy. The inhibitory effect of $\mathrm{Cu}$ ion on Ig production or immune response has also been reported in guinea pig (Boroskova et al., 1993) or in human (Bumgardner et al., 1993; Mehanna et al., 1994; Smith et al., 1996). These results suggest that $\mathrm{Cu}$ ion plays an important role in Ig production by human and other animals. As for $\mathrm{Fe}^{2+}$ ion, Schwartzer et al. (1992) reported that iron liberated from malarial pigment resulted in the lipid peroxidation. $\mathrm{Cu}^{2+}$ have also been reported to enhance peroxidation of unsaturated fatty acids (Albertini et al., 1996). These results suggest that lipid peroxidation enhanced by $\mathrm{Fe}^{2+}$ or $\mathrm{Cu}^{2+}$ ions plays an important role on the inhibition of $\operatorname{Ig} \mathrm{E}$ production.

\section{REFERENCES}

Albertini, R., S. Rindi, A. Passi, G. Pallavicini, and G. De Luca 1996 Heparin protection against Fe ${ }^{2+}$ and $\mathrm{Cu}^{3+}$-mediated oxidation of liposome., FEBS Letters, 383: 155-158.

Boroskova, Z., M. Benkova, J. Soltys, I. Krupicer, and K. Simo 1993 Effects of heavy metals emission on the cellular immunity of guinea pigs with experimental ascariosis., Veterinary Parasitol., 47: 245254.

Bumgardner, J. D., L. C. Lucas, M. W. Jr. Alverson, and A. B. Tilden 1993 Effects of copper-based dental casting alloys on two lymphocyte cell lines and the secretion of interleukin 2 and IgG., Dental Materials, 9: 85-90.

Duncan, D. B. 1955 Multiple range and multiple $\mathrm{F}$ test., Biometrics, 11: 1-42.

Kuramoto, Y., K. Yamada, O. Tsuruta, and M. Sugano 1996 Effect of natural food colorings on immunoglobulin production in vitro by rat spleen lymphocytes., Biosci. Biotech. Biochem., 60: 17121713.

Kuramoto, Y., K. Yamada, B. O. Lim, and M. Sugano 1997 Stimulating effect of xanthene dyes on 


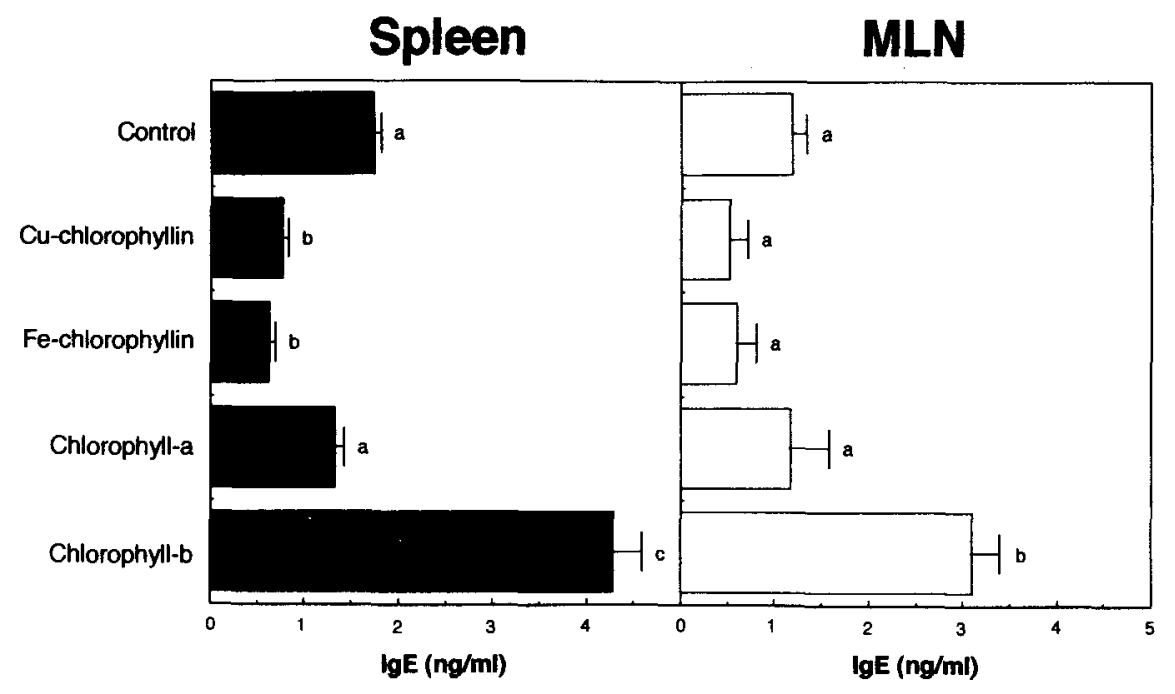

Fig. 5. Effect of chlorophylls and their derivatives on $\operatorname{IgE}$ produced by rat spleen or MLN lymphocytes. Cells were incubated for $72 \mathrm{hr}$ and culture supernatant was applied to ELISA $(n=4)$ to measure IgE concentration. "Values in the same group without a common letter are significantly different at $p<0.05$.

Effect of Chlorophyll Derivatives on Ig Production by Rat Spleen and MLN Lymphocytes.

Since sodium Cu-chlorophyllin showed an inhibitory effect of Ig production by both spleen and MLN lymphocytes, we investigated the effect of chlorophyll derivatives on Ig production by rat spleen and MLN lymphocytes. As chlorophyll derivatives, we selected sodium Cu-chlorophyllin, sodium Fe-chlorophyllin and two Mg-chlorophyllins (chlorophyll-a having methyl and phytyl groups and chlorophyll-b having aldehyde and phytyl groups). As shown in Fig. 5, both sodium Cu- and Fe-chlorophyllin inhibited IgE production by spleen lymphocytes at $100 \mu \mathrm{M}$. Among Mg-derivatives, chlorophyll-b enhanced IgE production by both lymphocytes, while chlorophyll-a had no effect on IgE production by these lymphocytes. These results suggest that minerals and aldehyde group in the porphyllin ring have an important role in the regulation of Ig production.

\section{DISCUSSION}

As a reason of the increase in allergic patients observed during the last decade in Japan, nany researchers have been studied on the relationship between environmental factors and allergy incidence. Takafuji et al. (1987 and 1989) and Takenaka et al. (1995) reported that DEP had an adjuvant effect on Ig production when the mixture of DEP and ovalbumin (OVA) is injected intraperitoneally or intranasally. However, only this factor can not explain the increase in allergy patients. Thus, we also studied on the relationship between food components and allergy incidence and found that Rose Bengal, a member of 
immunoglobulin produced in vitro by rat spleen lymphocytes., Biosci. Biotech. Biochem., 61: 723725.

Lim, B. O., K. Yamada, and M. Sugano 1994a Inhibition of immunoglobulin production in human Namalwa cells and rat spleen lymphocytes by bile acid., Biosci. Biotech. Biochem., 58: 1107-1111.

Lim, B. O., K. Yamada, and M. Sugano 1994b Effects of bile acids and lectins on immunoglobulin production in rat mesenteric lymph node lymphocytes., In Vitro Cell. Develop. Biol., 30A: 407-413.

Lim, B. O., K. Yamada, K. Yoshimura, T. Watanabe, P. Hung, S. Taniguchi, and M. Sugano 1995 Free bile acids inhibit IgE production by mouse spleen lymphocytes stimulated by lipopolysaccharide and interleukins., Biosci. Biotech. Biochem., 59:624-627.

Mehanna, M. T., M. A. Rizk, M. Ramadan, and J. Schachter 1994 Chlamydial serologic characteristics among intrauterine contraceptive device users: does copper inhibit chlamydial infection in the female genital tract?, Am. J. of Obstetrics \& Gynecol., 171: 691-693.

Metcalfe, D. D. 1991 Food allergy., Current Opinion Immunol, 3: 881-886.

Morales, C., M. Penarrocha, J. V. Bagan, E. Burches, and A. Pelaez 1995 Immunological study of Melkersson-Rosenthal syndrome. Lack of response to food additive challenge., Clinical \& Experimental Allergy, 25: 260-264.

Muranaka, M., S. Suzuki, K. Koizumi, S. Takafuji, and T. Miyamoto 1986 Adjuvant activity of dieselexhaust particulates for the production of IgE antibody in mice., J. Allergy Clin. Immunol., 77: 616 623.

Nish, W. A., B. A. Whisman, D. W. Goetz, and D. A. Ramirez 1991 Anaphylaxis to annatto dye: a case report., Ann. Allergy, 66: $129-131$.

Savage, S. M., L. A. Donaldson, S. Cherian, R. Chilukuri, V. A. White, and M. L. Sopori 1991 Effects of cigarette smoke on the immune response. I. Chronic exposure to cigarette smoke inhibits surface immunoglobulin-mediated responses in B cells., Toxicol. Appl. Pharmacol, 111: 523-529.

Schwarzer, E., F. Turrini, D. Ulliers, G. Giribaldi, H. Ginsburg, and P. Arese 1992 Impairment of macrophage functions after ingestion of Plasmodium falciparum-infected erythrocytes or isolated malarial pigment., J. Exp. Med., 176: 1033-1041.

Sinith, M. A., M. Easton, P. Everett, G. Lewis, M. Payne, V. Riveros-Moreno, and G. Allen 1996 Specific cleavage of immunoglobulin G by copper ions., Int. J. of Peptide \& Protein Res., 48: 48-55.

Steffensen, I. L., O. J. Mesna, E. Andruchow, E. Namork, K. Hylland, and R. A. Andersen 1994 Cytotoxicity and accumulation of $\mathrm{Hg}, \mathrm{Ag}, \mathrm{Cd}, \mathrm{Cu}, \mathrm{Pb}$ and $\mathrm{Zn}$ in human peripheral $\mathrm{T}$ and $\mathrm{B}$ lymphocytes and monocytes in vitro, General Pharmacol., 25: 1621-1633.

Takafuji, S., S. Suzuki, K. Koizumi, K. Tadokoro, T. Miyamoto, R. Ikemori, and M. Muranaka 1987 Dieselexhaust particulates inoculated by the intranasal route have an adjuvant activity for IgE production in mice., J. Allergy Clin. Immunol., 79: 639-645.

Takafuji, S., S. Suzuki, M. Muranaka, and T. Miyamoto 1989 Influence of environmental factors on IgE production., IgE, Mast Cells and the Allergic Response, Wiley, Chichester (Ciba Foundation Symposium 147), 188-204.

Takenaka, H., Z. Ke, D. Diaz-Sanchez, A. Tsien, and A. Saxon 1995 Enhanced human IgE production results from exposure to the aromatic hydrocarbons from diesel exhaust: Direct effects on B-cell $\operatorname{IgE}$ production., J. Allergy Clin. Immunol., 95: 103-115.

Tarlo, S. M. and G. L. Sussman 1993 Asthma and anaphylactoid reactions to food additives., Can. Fam. Physician, 39: 1119-1123.

Weber, R. W. 1993 Food additives and allergy., Ann. Allergy, 70: 183-192.

Wüthrich, B. 1993 Adverse reactions to food additives., Ann. Allergy, 71: 379-384.

Yamada, K., B. O. Lim, and M. Sugano 1993 Suppression of immunoglobulin production of rat lymphocytes by bile acids., In Vitro Cell. Develop. Biol., 29: 840-841. 